Article

\title{
Tools for In Vitro Propagation/Synchronization of the Liverwort Marchantia polymorpha and Application of a Validated HPLC-ESI-MS-MS Method for Glutathione and Phytochelatin Analysis
}

\author{
Silvia Giardini ${ }^{1}$, Erika Bellini ${ }^{1}{ }^{(D}$, Elena Bandoni ${ }^{1}$, Alessandro Saba ${ }^{2}\left(\mathbb{C}\right.$ and Luigi Sanità di Toppi ${ }^{1, *(\mathbb{C})}$ \\ 1 Dipartimento di Biologia, Università di Pisa, Via Luca Ghini 13, 56126 Pisa, Italy; \\ s.giardini1@studenti.unipi.it (S.G.); erika.bellini@biologia.unipi.it (E.B.); e.bandoni2@studenti.unipi.it (E.B.) \\ 2 Dipartimento di Patologia Chirurgica, Medica, Molecolare e dell'Area Critica, Università di Pisa, Via Roma 67, \\ 56126 Pisa, Italy; alessandro.saba@unipi.it \\ * Correspondence: luigi.sanita@unipi.it
}

Citation: Giardini, S.; Bellini, E.; Bandoni, E.; Saba, A.; Sanità di Toppi,

L. Tools for In Vitro Propagation/ Synchronization of the Liverwort Marchantia polymorpha and Application of a Validated HPLC-ESI-MS-MS Method for Glutathione and Phytochelatin Analysis. Stresses 2022, 2, 136-145. https://doi.org/10.3390/ stresses 2010010

Academic Editor: Anna Aksmann

Received: 29 December 2021

Accepted: 22 February 2022

Published: 24 February 2022

Publisher's Note: MDPI stays neutral with regard to jurisdictional claims in published maps and institutional affiliations.

Copyright: (C) 2022 by the authors. Licensee MDPI, Basel, Switzerland. This article is an open access article distributed under the terms and conditions of the Creative Commons Attribution (CC BY) license (https:// creativecommons.org/licenses/by/ $4.0 /)$.

\begin{abstract}
Bryophytes, due to their poikilohydric nature and peculiar traits, are useful and versatile organisms for studies on metal accumulation and detoxification in plants. Among bryophytes, the liverwort Marchantia polymorpha is an excellent candidate as a model organism, having a key role in plant evolutionary history. In particular, M. polymorpha axenic cultivation of gametophytes offers several advantages, such as fast growth, easy propagation and high efficiency of crossing. Thus, the main purpose of this work was to promote and validate experimental procedures useful in the establishment of a standardized set-up of M. polymorpha gametophytes, as well as to study cadmium detoxification processes in terms of thiol-peptide production, detection and characterisation by HPLCmass spectrometry. The results show how variations in the composition of the Murashige and Skoog medium impact the growth rate or development of this liverwort, and what levels of glutathione and phytochelatins are produced by gametophytes to counteract cadmium stress.
\end{abstract}

Keywords: Marchantia polymorpha; vegetative propagation; abiotic stress; heavy metals; cadmium; thiol-peptides; HPLC-ESI-MS-MS

\section{Introduction}

Heavy metals are ubiquitous chemical elements present in all environmental matrices (soil, water, atmosphere), derived from both natural sources (e.g., pedogenetic processes) and anthropogenic emissions (e.g., as a byproduct of industrial activities, vehicle traffic, heating systems, etc.) [1,2]. Some studies have shown that, in nature, there is a correspondence between heavy metal and vegetation cover [3], which could offer an interesting reading key for future research in this field. The polluting capacity of heavy metals is due to their intrinsic toxicity combined with their long persistence, high solubility and ability to accumulate in organisms in higher concentrations than in the surrounding environment [2,4]. Historically, the term "heavy metals" indicates all transition elements with a density higher than $5 \mathrm{~g} \mathrm{~cm}^{-3}$ [2], although further methods of classification have recently been put forward, based on their affinity with functional groups such as thiols, carboxyls and amines [5].

The heavy metals which are toxic for plants, animals and the vast majority of organisms are cadmium $(\mathrm{Cd})$, hexavalent chromium $(\mathrm{CrVI})$, mercury $(\mathrm{Hg})$, lead $(\mathrm{Pb})$ and thallium $(\mathrm{Tl})$, among others. However, certain heavy metals, such as iron $(\mathrm{Fe})$, zinc $(\mathrm{Zn})$, copper $(\mathrm{Cu})$, molybdenum (Mo) and manganese (Mn), below a specific toxicity threshold, are indeed essential nutrients. For this reason, plants have evolved specific mechanisms for regulating essential metal uptake while avoiding deficiencies and toxicity effects [6]. 
In particular, bryophytes (including Marchantiophyta, Bryophyta and Anthocerotophyta) might prove to be useful model organisms for gaining a better understanding of metal accumulation and detoxification processes in plants [5,7]. Due to their poikilohydric nature, bryophytes do not possess strong hydrophobic barriers. Therefore, all nutrients and toxic elements can be absorbed by their entire body [7]. Moreover, because of their morpho-physiological characteristics, they can often be used as environmental biomonitors, particularly for monitoring air and precipitation quality $[8,9]$.

Among bryophytes, the thalloid liverwort Marchantia polymorpha L. subsp. ruderalis Bischl. and Boisselier-Dubayle is currently recognized as an excellent model organism in studies of land plant evolution and phylogeny [10,11]. This liverwort is a dioecious species, having male and female gametophytes that can reproduce in a sexual or asexual manner. Clonal reproduction of M. polymorpha involves the formation of multicellular gemmae within gemmae "cups," which are present on the dorsal part of the mature gametophyte, generally at each bifurcation [10]. Transplanted gemmae are able to develop, and, under axenic conditions, give rise to new clonal organisms $[12,13]$. Progress in transformation techniques [14-17] and the sequencing of the entire genome (about $280 \mathrm{Mb}$; [11]) have further promoted the use of M. polymorpha as a fundamental model organism in functional, molecular and evolutionary studies on land plants. Indeed, M. polymorpha gametophytes offer several advantages, such as a short life cycle, a relatively small genome size and a haploid number of chromosome sets. In addition, they can be easily cultivated and propagated axenically, avoiding genetic and metabolic variability from sexual processes or interaction with other organisms [16]. M. polymorpha could thus prove an excellent model organism for investigating the molecular and cellular process linked to heavy metal detoxification. Among these mechanisms, a key role is played by phytochelatins (PCn), small thiol-peptides whose general structure is $(\gamma \text {-Glu-Cys })_{n}$-Gly $(n=2-5)[18,19]$. PCn mediate free metal chelation in cytosol and subsequent transport into the vacuole to avoid the free circulation of metal ions, thereby reducing their toxic effect. PCn synthesis is catalyzed by the phytochelatin synthase (PCS) enzyme, a gamma-glutamylcysteine-dipeptidyl(trans)peptidase, belonging to the "Clan CA" of papain-like cysteine proteases [20-23]. It has been demonstrated that this enzyme's activity is linked to the presence of heavy metals such as cadmium $(\mathrm{Cd})$, mercury $(\mathrm{Hg})$ and lead $(\mathrm{Pb})$, as well as the metalloid arsenic (As) $[19,24,25]$. Recently, PCS activation has not only been detected in tracheophytes (chiefly in angiosperms), but also in bryophytes and charophytes, in response to metallic micronutrients such as $\mathrm{Fe}, \mathrm{Zn}, \mathrm{Cu}$ and the toxic metal $\mathrm{Cd}$ [26-28]. Moreover, as proposed by Maresca et al. (2020) [29], their role as metal detoxifier could make PCn indicators of metal stress, and biomarkers for monitoring such stress in plants. This demands the validation of PCn analytic methods which could be reliably employed with various plant systems.

Accordingly, the principal aims of this work are to clarify how M. polymorpha could be grown in axenic conditions, and to examine aspects of its ability to detoxify heavy metals using a validated mass spectrometry method.

\section{Results and Discussion}

\subsection{The In Vitro Propagation Protocol Employed Enables Rapid Synchronization of Gametophyte Growth}

In this work, we tested two alternative methods of vegetative propagation of M. polymorpha gametophytes, both using a Murashige and Skoog half-strength (MS 1/2) medium, pH 5.7 (Figure 1).

In the first case, propagation commenced with gemmae taken from gemmae cups. The gemmae were produced in large quantities in cups, and were clones of the organism from which they were generated $[12,13]$. The gemmae, which were placed in a solid MS 1/2 medium and exposed to a light source, promptly developed and yielded a genetically identical clone. The results clearly showed that sucrose was fundamental for the gemmae to grow and develop into a new gametophyte (Figure 1). Indeed, as reported by Ishizaki et al. (2016) [30], sucrose is also essential for gemmae cup formation, which in 
turn depends on environmental factors and nutrients in the medium. Sucrose appears to contribute to cell cycle progression [31,32] and plays an important role in maintaining the gametophyte culture.

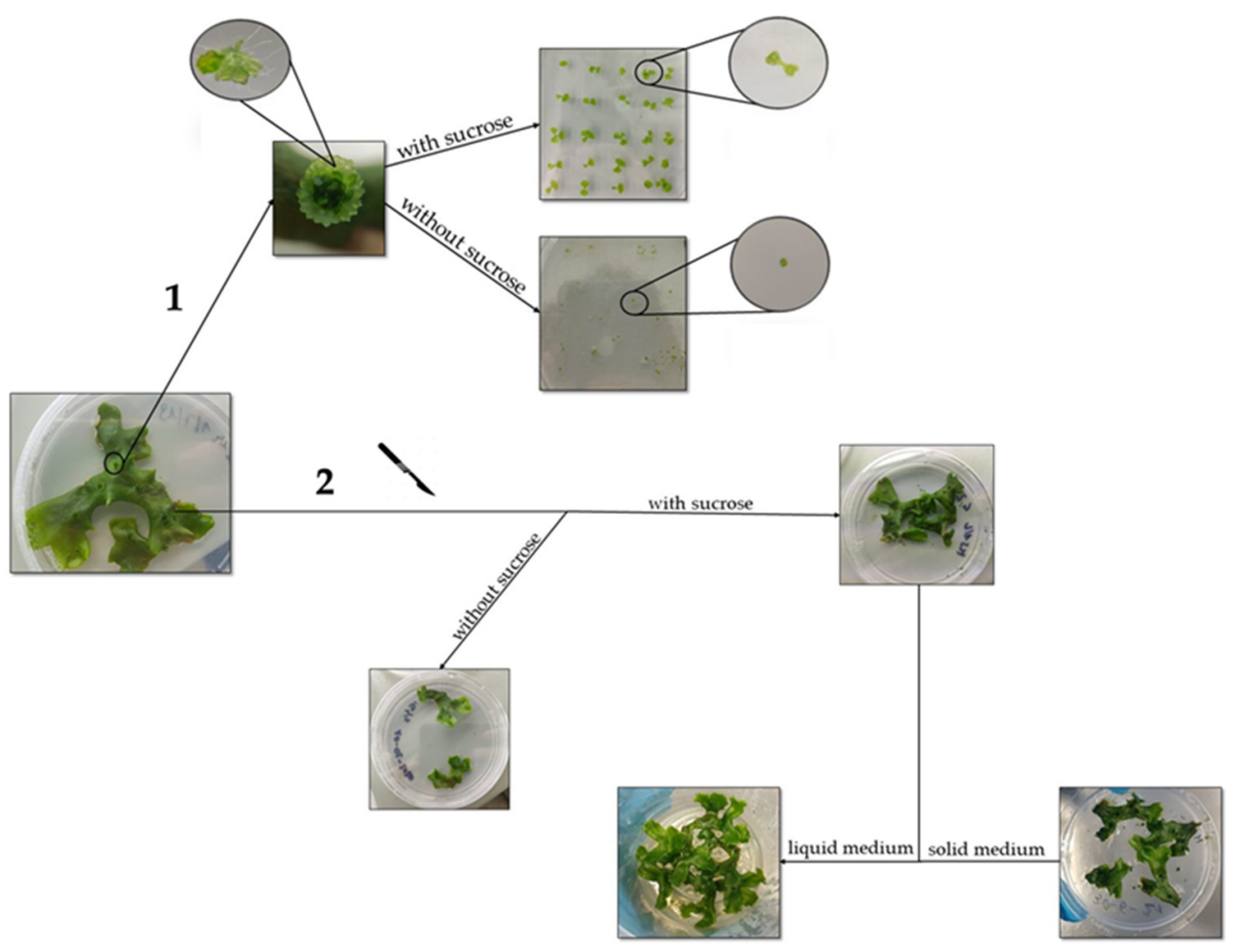

Figure 1. Two alternative vegetative propagation methods of $M$. polymorpha gametophytes: (1) from gemmae cultivated in solid MS 1/2 medium, with or without sucrose; (2) from portions of the gametophyte, propagated with and without sucrose in solid MS 1/2 medium, or supplied with sucrose in liquid MS $1 / 2$ medium.

The second propagation method was based on cutting off the part of the gametophyte whose lobes contained the meristem [30]. One considerable advantage of M. polymorpha as a model organism is that a small part of the gametophyte suffices for regenerating the entire one, without the need for any growth regulator [16,33]. However, regenerated gametophytes grown in the absence of sucrose showed a significantly lower growth rate than those grown with sucrose (Figure 1). Once gametophytes of an appropriate size were obtained, particularly with sucrose addition, they could either be grown in a liquid medium using pots, or in a solid medium using Petri dishes, as shown in Figure 1.

After 2 weeks of cultivation, the differences between the growth rates of gametophytes grown in liquid and solid mediums were observed (Figure 2). In fact, the gametophytes grew faster in a liquid medium than in solid MS 1/2, becoming larger in size (Figure 2a).

This increased growth rate could likely be attributed to the greater facilitation of nutrient acquisition in the liquid medium than in the solid one. It is important to note that a liquid medium is suitable for metal treatment as it enables the homogeneous, enhanced absorption of the elements contained in the medium. 


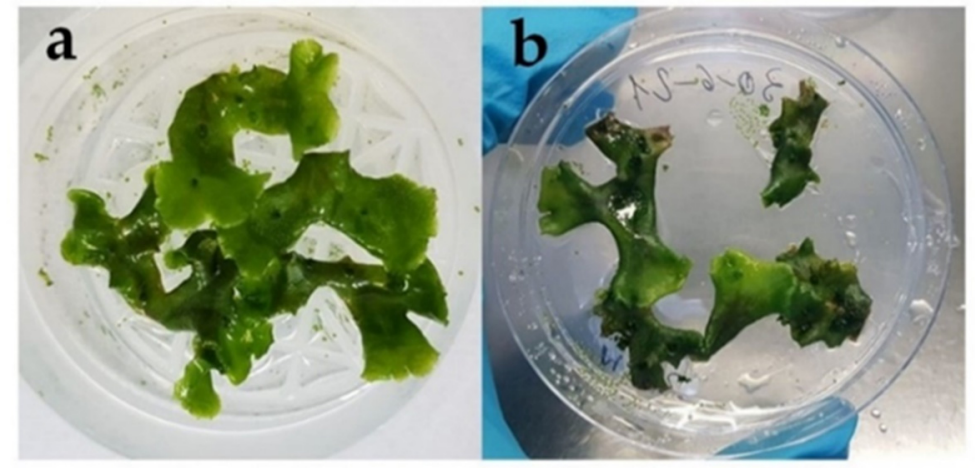

Figure 2. M. polymorpha growth after 2 weeks in liquid (a) and solid (b) MS 1/2 medium, supplied with sucrose.

\subsection{Gametophytes of M. polymorpha Lead to Rapid Medium Acidification}

It has been widely demonstrated that the growth of plants may result in the acidification of the environment where they live [34]. In fact, acidification of the medium seems to increase the availability and acquisition of nutrients used for the organism's growth. The $\mathrm{pH}$ value of the liquid MS $1 / 2$ medium (initially set to a $\mathrm{pH}$ value equal to 5.7) was accordingly measured while growing our cultures, to understand the mechanisms behind the faster growth of $M$. polymorpha in the liquid medium. These data were monitored for 20 days in the liquid medium where M. polymorpha gametophytes were growing. The results are shown in Figure 3.

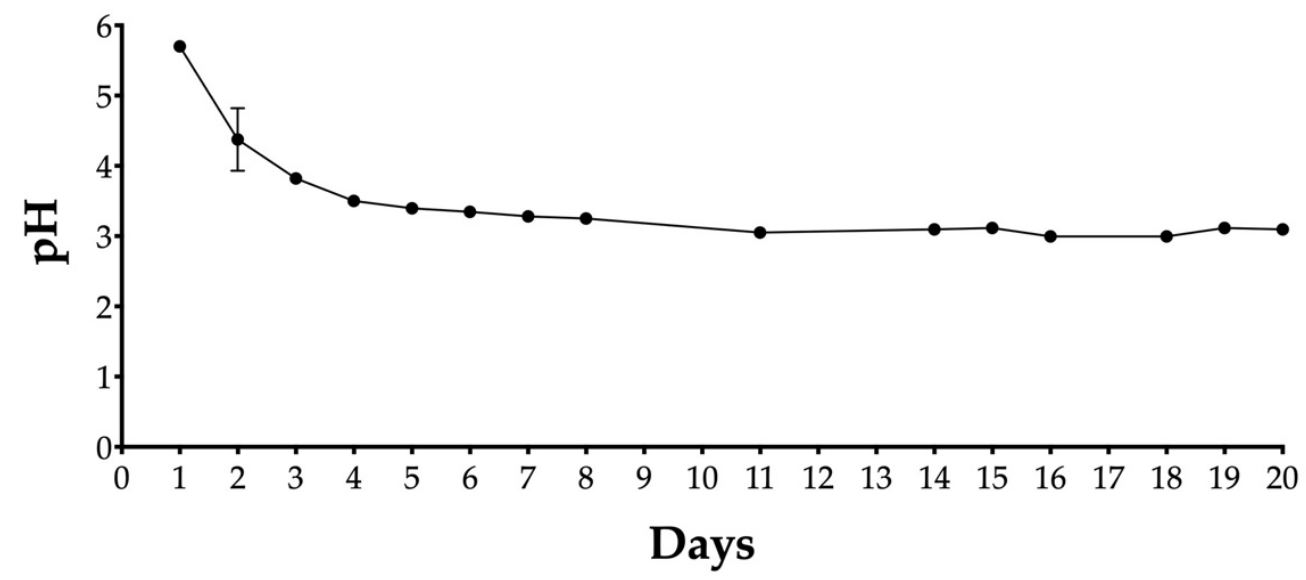

Figure 3. $\mathrm{pH}$ values detected over 20 days in pots used for growing M. polymorpha in liquid MS 1/2 medium, containing sucrose. Values are mean $\pm \mathrm{SE}$.

Interestingly, a rapid lowering of $\mathrm{pH}$ was already detected after the first $24 \mathrm{~h}$ of growth, reaching values of around 4.4. After additional few days, the $\mathrm{pH}$ progressively dropped to a value of 3.5-3.2, and remained constant around this value over the following days (Figure 3). The strong acidification observed in M. polymorpha cultures was also recorded by Rico-Resendiz and colleagues [35] under phosphate starvation conditions, highlighting that acidification can be a mechanism for increasing nutrient availability. Acidification of the medium could be due to the extrusion of metabolites such as organic acids by M. polymorpha gametophytes. It is well known that bryophytes produce large amounts of secondary metabolites [36]. The functions of many of these metabolites are not clearly understood, and many processes still need to be clarified. As a result, in the future, we aim to investigate which molecules extruded by M. polymorpha gametophytes might be responsible for the strong acidification of the medium. 


\subsection{The Extraction Procedure and the Analytical Method Used Allow an Effective Quali-} Quantitative Analysis of Thiol-Peptides in M. polymorpha Gametophytes

Liverworts are known for their ability to accumulate heavy metals in high concentrations through chelation and passive ion exchange mechanisms [5,7]. Their large surface/volume ratio allows them to efficiently absorb water and dissolved elements from the entire surface of the gametophyte [37]. As a result, liverworts such as M. polymorpha appear optimal for studying the mechanisms leading to metal detoxification. One such mechanism is the induction of the ubiquitous PCS enzyme, which is known to be constitutively expressed and fully activated in the presence of metal(loid)s, even in bryophytes and other early diverging streptophytes $[26-28,38]$. However, it should be noted that the extraction, characterization and quantification of analytes in plant extracts are often challenging due to the considerable variability in biological and instrumental terms. This is particularly the case of bryophytes, which produce large amounts of secondary metabolites [39,40]. The analysis of thiol-peptides is particularly critical due to their sensitivity to oxidation reactions, which frequently involve the formation of inter- and intra-molecular disulphide bonds during sample preparation or storage [41,42].

In this work, we tested the method used for thiol-peptide extraction and analysis in HPLC-ESI-MS-MS, as previously validated with Arabidopsis thaliana [42], in M. polymorpha gametophytes. Although slight alterations were made to the extraction procedure, such as adding a semi-purification step to reduce secondary metabolite interference, the method enabled the accurate characterization and quantification of GSH and PCn in M. polymorpha samples using HPLC-ESI-MS-MS analyses, as shown in Figure 4.

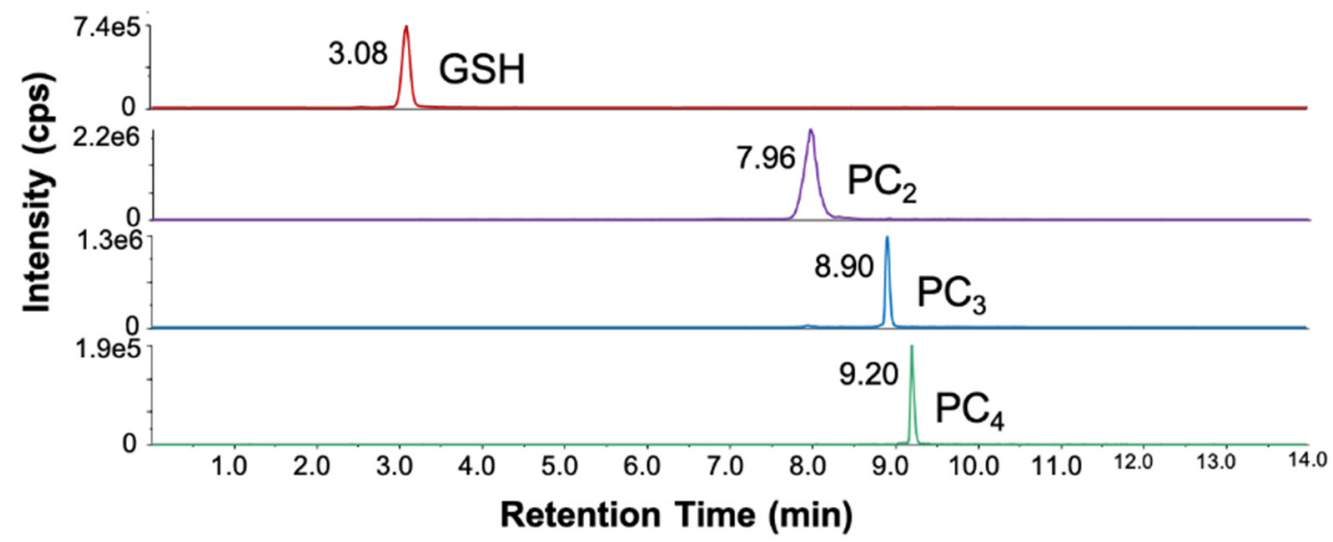

Figure 4. Representative mass spectrometry chromatograms of a partially purified extract from M. polymorpha in the time range of 0-14 $\mathrm{min}$.

The results of the in vivo quantification of the thiol-peptides were consistent with those obtained by Bellini et al. (2020) (Figure 5) [43]. Indeed, the constitutive levels of GSH in the liverwort were somewhat lower than those normally found in higher plants, but wholly comparable with those quantified in other liverworts [26,27]. The sole exception is Pellia epiphylla, which is the only species with GSH levels 6-60 times higher than those of other liverworts [27], M. polymorpha included. In our experiments, the GSH levels increased under $\mathrm{Cd}$ treatments, possibly reflecting re-synthesis by the glutathione synthase enzyme and/or the reduction of oxidized glutathione (GSSG) by the NADPH-dependent glutathione reductase. Indeed, this thiol-tripeptide is a ubiquitous molecule in all organisms and is involved in a plethora of cellular responses, mainly functioning as an antioxidant and regulator of redox homeostatic processes [44,45]. With regard to PCn, the data confirmed the constitutive basal activity of M. polymorpha PCS [43], with control plants producing only $\mathrm{PC}_{2}$ (Figure 5). At all concentrations, the presence of Cd resulted in M. polymorpha PCS being promptly activated, with $\mathrm{PC}_{2}, \mathrm{PC}_{3}$ and $\mathrm{PC}_{4}$ synthesis (Figure 5). For total PCn, the observations seem to support an increasing trend in the production of $\mathrm{PCn}$ as the $\mathrm{Cd}$ concentrations grow. It is also important to note that the degree of polymerization of PCn 
is directly proportional to their chelating power, which depends on the number of thiol groups in the molecular structure [46]. Interestingly, as far as we know, PCn up to $\mathrm{PC}_{4}$ have only been detected in Conocephalum conicum and Lunularia cruciata liverworts [26,27], whereas in all the other species assayed so far, $\mathrm{PC}$ production has been limited to only $\mathrm{PC}_{2}$ (and to $\mathrm{PC}_{2}$ and $\mathrm{PC}_{3}$ in just one case) [27]. This may be due to the actual non-production of PCn with high polymerization levels in other liverwort species, or to the fact that a nonoptimized analytical method was adopted. As mentioned above, high levels of secondary metabolites in the extracts may actually generate a strong matrix effect, resulting in the masking of the analytes and causing a considerable reduction in the sensitivity of the method used [42].

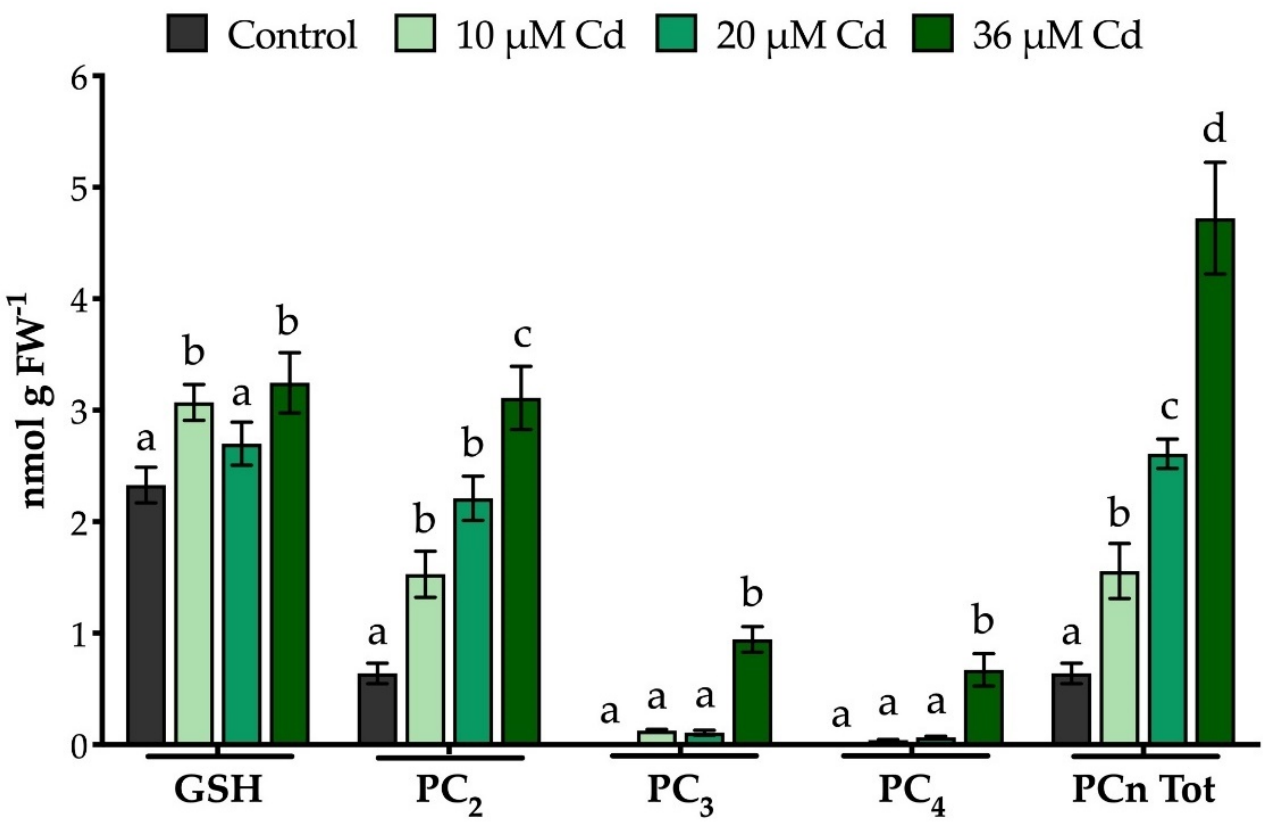

Figure 5. Thiol-peptide content detected in M. polymorpha gametophytes (control and treated plants with 10, 20 and $36 \mu \mathrm{M} \mathrm{Cd}^{2+}$ for $72 \mathrm{~h}$ ). Values are mean \pm SE. Differences between levels of thiolpeptides were detected by one-way analysis of variance (ANOVA), followed by Tukey's multiple comparison post hoc test. Within each group of thiol-peptides, bars not accompanied by the same letter are significantly different at $p<0.05$.

\section{Materials and Methods}

\subsection{Set-Up of the In Vitro Cultures, Growth Conditions and Vegetative Propagation of M. polymorpha Gametophytes}

Axenic cultures of Marchantia polymorpha L. subsp. ruderalis Bischl. and Boisselier-Dubayle (Marchantiales, Marchantiophyta) female gametophytes (Cam2-Cambridge-2 wild type, University of Cambridge, UK) were grown both in a liquid medium using pots and in a solid medium using Petri dishes ( $100 \mathrm{~mm}$ ). In both cases, sterile half-strength (1/2) Murashige \& Skoog (MS) medium was used, $\mathrm{pH} 5.7$, supplemented with $0.8 \%(w / v)$ sucrose (Duchefa Biochemie). In the pots, $200 \mathrm{~mL}$ of liquid medium was employed, whereas in each Petri dish the volume used totalled $20 \mathrm{~mL}$, supplemented with $0.7 \%(w / v)$ Plant Agar (Duchefa Biochemie). Gametophytes in dishes and pots were placed in a growth chamber with a light/dark cycle of $16: 8 \mathrm{~h}$ with a photosynthetic photon flux density of $60 \mu \mathrm{mol} \mathrm{m}{ }^{-2} \mathrm{~s}^{-1}$, a temperature of $19 \pm 1{ }^{\circ} \mathrm{C}$ and $60 \%$ relative humidity. The gametophytes were propagated from gemmae (collected from gemmae cups) in a solid MS 1/2 medium, or from pieces cut from the gametophyte and propagated using a solid or liquid medium. The axenic cultures of gametophytes were set up and propagated using sterile forceps and scalpel under a vertical laminar flow. Sterilization of the scalpel blade and forceps was performed using a glass bead sterilizer at $300{ }^{\circ} \mathrm{C}$. The scalpel and forceps were then cooled using sterilized 
filter paper soaked with sterile deionized water. After that, the instruments were used immediately for handling the plant material.

\subsection{Metal Treatments and $p H$ Measurements}

Axenic gametophytes started from gemmae were grown in a solid MS $1 / 2$ medium for 6 weeks and transferred into fresh dishes every 2 weeks. The resulting gametophytes were moved into sterile pots filled with $200 \mathrm{~mL}$ of liquid MS 1/2 medium and left to grow for a further week to acclimatize to the new conditions. After 1 week in the liquid medium, 7-week-old gametophytes (about $0.8 \mathrm{~g}$ FW) were independently moved to Petri dishes $(\varnothing 60 \mathrm{~mm}$ ) with $5 \mathrm{~mL}$ of liquid MS 1/2 medium, $\mathrm{pH} 5.7$, and placed in different treatment conditions. Control samples with homeostatic concentrations of micronutrients corresponding to the same concentrations in the MS $1 / 2$ medium were set up. Samples treated with $\mathrm{Cd}$ had the following concentrations: 10, 20 and $36 \mu \mathrm{M} \mathrm{Cd}^{2+}$ (provided as $3 \mathrm{CdSO}_{4} \cdot 8 \mathrm{H}_{2} \mathrm{O}$ ) for $72 \mathrm{~h}$. Five biological replicates were performed for both the control samples and treated ones. At the end of the exposure time, the gametophytes were collected, dried with filter paper, divided into samples with a fresh weight of $100 \mathrm{mg}$, frozen in liquid nitrogen and stored at $-80{ }^{\circ} \mathrm{C}$ for further analyses. The $\mathrm{pH}$ values of the liquid $\mathrm{MS} 1 / 2$ medium were measured to gauge whether they had been influenced by $\mathrm{Cd}$ or not. The $\mathrm{pH}$ of the liquid half-strength MS medium was measured in the dishes and in the pots during growth of gametophytes, and at the end of each treatment.

\subsection{Extraction, Characterization and Quantification of Thiol-Peptides}

Gametophyte samples of $100 \mathrm{mg}$ FW, previously stored at $-80{ }^{\circ} \mathrm{C}$, were extracted mainly following Bellini et al. (2019) [42], with slight modifications. Briefly, each sample was ground into a powder using liquid nitrogen, a mixer mill (MM200, Retsch, Haan, Germany) and two agate grinding balls $(\varnothing 5 \mathrm{~mm})$ to facilitate mechanical cell breakage using a frequency of $30 \mathrm{~Hz}$ for $1 \mathrm{~min}$. Then, $300 \mu \mathrm{L}$ of a previously prepared and ice-cool extraction buffer (5\% $w / v$ of salicylsulfonic acid, $6.3 \mathrm{mM}$ of diethylenetetraminopentaacetic acid (DTPA) and $2 \mathrm{mM}$ of tris (2-carboxyethyl) phosphine acid (TCEP)) were added to each sample, together with $200 \mathrm{ng} \mathrm{mL} \mathrm{mL}^{-1}$ of internal standards (GSH and $\mathrm{PC}_{2}$ ), which had glycine marked with stable isotopes $\left({ }^{15} \mathrm{~N},{ }^{13} \mathrm{C}\right.$ ): ${ }^{13} \mathrm{C}_{2},{ }^{15} \mathrm{~N}-\mathrm{GSH}$ and ${ }^{13} \mathrm{C}_{2},{ }^{15} \mathrm{~N}-\mathrm{PC}_{2}$ (AnaSpec Inc., Fremont, CA, USA) The suspension obtained was vortexed for $30 \mathrm{~s}$, kept in an ice bath for $15 \mathrm{~min}$ and vortexed every $5 \mathrm{~min}$. The extract was then centrifuged at $20,000 \times g$ (Hermle, Z $300 \mathrm{~K}$, Wehingen, Germany) for $20 \mathrm{~min}$ at $4{ }^{\circ} \mathrm{C}$. Unlike the results published by Bellini et al. (2019) [42], in this work, each supernatant was semi-purified using Amicon Ultracentrifuge filters $(10 \mathrm{kDa})$ as an alternative to Minisart RC4 $0.45 \mu \mathrm{m}$ filters (Sartorius, Goettingen, Germany) to reduce any matrix effect. The samples were centrifuged at $14,000 \times g$ (Hermle, Z $300 \mathrm{~K}$, Wehingen, Germany) for $30 \mathrm{~min}$ at $4{ }^{\circ} \mathrm{C}$ using Amicon Ultracentrifuge filters $(10 \mathrm{kDa})$. The flow-through was then saved. Samples were stored at $-80^{\circ} \mathrm{C}$ until analyzed in HPLC-ESI-MS-MS, which was conducted using the analytical method validated by Bellini et al. (2019) [42].

\section{Conclusions}

The in vitro growth and cultivation in axenic conditions of model plants such as the liverwort M. polymorpha can represent an important basis for the development of effective protocols useful for investigating the functional and molecular responses of early diverging streptophytes to toxic heavy metals, such as $\mathrm{Cd}$. In this work, we developed a reliable in vitro cultivation protocol of $M$. polymorpha gametophytes. Moreover, we characterized this liverwort with respect to medium acidification, as well as its thiol-peptide production (GSH, PCn) following Cd supply for $72 \mathrm{~h}$. The data collected may prove to be a reference point for any future study involving the model organism $M$. polymorpha. It may be of interest to evaluate the nature of molecules extruded by this liverwort that result in acidification of the growth medium, in order to deepen the causes of this process. In addition, M. polymorpha can be used to define the molecular and cellular pathways of heavy metal detoxification 
and the repair of damage caused by the induced stress. Therefore, it could be interesting to investigate the role of tonoplast and plasmalemma transporters involved in heavy metal movement across membranes, either as free ions or complexed to thiol-peptides. Overall, M. polymorpha represents an excellent model system for evolutionary, functional, molecular and biomonitoring studies of heavy metals present in the environment.

Author Contributions: Conceptualization, L.S.d.T. and E.B. (Erika Bellini); methodology, S.G. and E.B. (Elena Bandoni); validation, A.S. and L.S.d.T.; formal analysis, S.G., E.B. (Erika Bellini) and A.S.; investigation, L.S.d.T.; data curation, S.G., E.B. (Erika Bellini) and E.B. (Elena Bandoni); writingoriginal draft preparation, S.G., E.B. (Erika Bellini) and L.S.d.T.; writing-review and editing, S.G., E.B. (Erika Bellini), A.S. and L.S.d.T.; supervision, A.S. and L.S.d.T.; project administration, L.S.d.T. All authors have read and agreed to the published version of the manuscript.

Funding: This research received no external funding.

Conflicts of Interest: The authors declare no conflict of interest.

\section{References}

1. Frausto da Silva, J.J.R.; Williams, R.J.P. The Biological Chemistry of the Elements: The Inorganic Chemistry of Life; OUP Oxford: Oxford, UK, 2001; ISBN 978-0-19-850848-9.

2. Sanità di Toppi, L.; Gabbrielli, R. Response to Cadmium in Higher Plants. Environ. Exp. Bot. 1999, 41, 105-130. [CrossRef]

3. Perrino, E.V.; Brunetti, G.; Farrag, K. Plant Communities in Multi-Metal Contaminated Soils: A Case Study in the National Park of Alta Murgia (Apulia Region - Southern Italy). Int. J. Phytoremed. 2014, 16, 871-888. [CrossRef]

4. Tchounwou, P.B.; Yedjou, C.G.; Patlolla, A.K.; Sutton, D.J. Heavy Metal Toxicity and the Environment. In Molecular, Clinical and Environmental Toxicology: Volume 3: Environmental Toxicology; Luch, A., Ed.; Experientia Supplementum; Springer: Basel, Swizterland, 2012; pp. 133-164; ISBN 978-3-7643-8340-4.

5. Stanković, J.D.; Sabovljević, A.D.; Sabovljević, M.S. Bryophytes and Heavy Metals: A Review. Acta Bot. Croat. 2018, 77, 109-118. [CrossRef]

6. Tennstedt, P.; Peisker, D.; Böttcher, C.; Trampczynska, A.; Clemens, S. Phytochelatin Synthesis Is Essential for the Detoxification of Excess Zinc and Contributes Significantly to the Accumulation of Zinc. Plant Physiol. 2009, 149, 938-948. [CrossRef]

7. Bellini, E.; Betti, C.; Sanità di Toppi, L. Responses to Cadmium in Early-Diverging Streptophytes (Charophytes and Bryophytes): Current Views and Potential Applications. Plants 2021, 10, 770. [CrossRef]

8. Harmens, H.; Ilyin, I.; Mills, G.; Aboal, J.R.; Alber, R.; Blum, O.; Coşkun, M.; De Temmerman, L.; Fernández, J.Á.; Figueira, R.; et al. Country-Specific Correlations across Europe between Modelled Atmospheric Cadmium and Lead Deposition and Concentrations in Mosses. Environ. Pollut. 2012, 166, 1-9. [CrossRef]

9. Shaw, J. Evolution of Heavy Metal Tolerance in Bryophytes Ii. an Ecological and Experimental Investigation of the "Copper Moss," Scopelophila cataractae (Pottiaceae). Am. J. Bot. 1987, 74, 813-821. [CrossRef]

10. Shimamura, M. Marchantia polymorpha: Taxonomy, Phylogeny and Morphology of a Model System. Plant Cell Physiol. 2016, 57, 230-256. [CrossRef]

11. Bowman, J.L.; Kohchi, T.; Yamato, K.T.; Jenkins, J.; Shu, S.; Ishizaki, K.; Yamaoka, S.; Nishihama, R.; Nakamura, Y.; Berger, F.; et al. Insights into Land Plant Evolution Garnered from the Marchantia polymorpha Genome. Cell 2017, 171, 287-304.e15. [CrossRef]

12. Berger, F.; Bowman, J.L.; Kohchi, T. Marchantia. Curr. Biol. 2016, 26, R186-R187. [CrossRef]

13. Nakazato, T.; Kadota, A.; Wada, M. Photoinduction of Spore Germination in Marchantia polymorpha L. Is Mediated by Photosynthesis. Plant Cell Physiol. 1999, 40, 1014-1020. [CrossRef]

14. Ishizaki, K.; Chiyoda, S.; Yamato, K.T.; Kohchi, T. Agrobacterium-Mediated Transformation of the Haploid Liverwort Marchantia polymorpha L., an Emerging Model for Plant Biology. Plant Cell Physiol. 2008, 49, 1084-1091. [CrossRef]

15. Ishizaki, K.; Johzuka-Hisatomi, Y.; Ishida, S.; Iida, S.; Kohchi, T. Homologous Recombination-Mediated Gene Targeting in the Liverwort Marchantia polymorpha L. Sci. Rep. 2013, 3, 1532. [CrossRef]

16. Kubota, A.; Ishizaki, K.; Hosaka, M.; Kohchi, T. Efficient Agrobacterium -Mediated Transformation of the Liverwort Marchantia polymorpha Using Regenerating Thalli. Biosci. Biotechnol. Biochem. 2013, 77, 167-172. [CrossRef]

17. Sugano, S.S.; Shirakawa, M.; Takagi, J.; Matsuda, Y.; Shimada, T.; Hara-Nishimura, I.; Kohchi, T. CRISPR/Cas9-Mediated Targeted Mutagenesis in the Liverwort Marchantia polymorpha L. Plant Cell Physiol. 2014, 55, 475-481. [CrossRef]

18. Bräutigam, A.; Schaumlöffel, D.; Krauss, G.-J.; Wesenberg, D. Analytical Approach for Characterization of Cadmium-Induced Thiol Peptides-a Case Study Using Chlamydomonas reinhardtii. Anal. Bioanal. Chem. 2009, 395, 1737-1747. [CrossRef]

19. Grill, E.; Löffler, S.; Winnacker, E.-L.; Zenk, M.H. Phytochelatins, the Heavy-Metal-Binding Peptides of Plants, Are Synthesized from Glutathione by a Specific $\gamma$-Glutamylcysteine Dipeptidyl Transpeptidase (Phytochelatin Synthase). Proc. Natl. Acad. Sci. USA 1989, 86, 6838-6842. [CrossRef]

20. Rea, P.A. Phytochelatin Synthase: Of a Protease a Peptide Polymerase Made. Physiol. Plant. 2012, 145, 154-164. [CrossRef] 
21. Romanyuk, N.D.; Rigden, D.J.; Vatamaniuk, O.K.; Lang, A.; Cahoon, R.E.; Jez, J.M.; Rea, P.A. Mutagenic Definition of a PapainLike Catalytic Triad, Sufficiency of the N-Terminal Domain for Single-Site Core Catalytic Enzyme Acylation, and C-Terminal Domain for Augmentative Metal Activation of a Eukaryotic Phytochelatin Synthase. Plant Physiol. 2006, 141, 858-869. [CrossRef]

22. Vivares, D.; Arnoux, P.; Pignol, D. A Papain-like Enzyme at Work: Native and Acyl-Enzyme Intermediate Structures in Phytochelatin Synthesis. Proc. Natl. Acad. Sci. USA 2005, 102, 18848-18853. [CrossRef]

23. Rea, P.A.; Vatamaniuk, O.K.; Rigden, D.J. Weeds, Worms, and More. Papain's Long-Lost Cousin, Phytochelatin Synthase. Plant Physiol. 2004, 136, 2463-2474. [CrossRef]

24. Clemens, S. Toxic Metal Accumulation, Responses to Exposure and Mechanisms of Tolerance in Plants. Biochimie 2006, 88, 1707-1719. [CrossRef]

25. Vatamaniuk, O.K.; Mari, S.; Lu, Y.-P.; Rea, P.A. Mechanism of Heavy Metal Ion Activation of Phytochelatin (PC) Synthase. J. Biol. Chem. 2000, 275, 31451-31459. [CrossRef]

26. Degola, F.; De Benedictis, M.; Petraglia, A.; Massimi, A.; Fattorini, L.; Sorbo, S.; Basile, A.; Sanità di Toppi, L. A Cd/Fe/ZnResponsive Phytochelatin Synthase Is Constitutively Present in the Ancient Liverwort Lunularia cruciata (L.) Dumort. Plant Cell Physiol. 2014, 55, 1884-1891. [CrossRef]

27. Petraglia, A.; De Benedictis, M.; Degola, F.; Pastore, G.; Calcagno, M.; Ruotolo, R.; Mengoni, A.; Sanità di Toppi, L. The Capability to Synthesize Phytochelatins and the Presence of Constitutive and Functional Phytochelatin Synthases Are Ancestral (Plesiomorphic) Characters for Basal Land Plants. J. Exp. Bot. 2014, 65, 1153-1163. [CrossRef]

28. Fontanini, D.; Andreucci, A.; Ruffini Castiglione, M.; Basile, A.; Sorbo, S.; Petraglia, A.; Degola, F.; Bellini, E.; Bruno, L.; Varotto, C.; et al. The Phytochelatin Synthase from Nitella mucronata (Charophyta) Plays a Role in the Homeostatic Control of Iron(II)/(III). Plant Physiol. Biochem. 2018, 127, 88-96. [CrossRef]

29. Maresca, V.; Sorbo, S.; Loppi, S.; Funaro, F.; Del Prete, D.; Basile, A. Biological Effects from Environmental Pollution by Toxic Metals in the "Land of Fires" (Italy) Assessed Using the Biomonitor Species Lunularia cruciata L. (Dum). Environ. Pollut. 2020, 265, 115000. [CrossRef]

30. Ishizaki, K.; Nishihama, R.; Yamato, K.T.; Kohchi, T. Molecular Genetic Tools and Techniques for Marchantia Polymorpha Research Plant Cell Physiol. 2016, 57, 262-270. [CrossRef]

31. Riou-Khamlichi, C.; Menges, M.; Healy, J.M.S.; Murray, J.A.H. Sugar Control of the Plant Cell Cycle: Differential Regulation of Arabidopsis D-Type Cyclin Gene Expression. Mol. Cell. Biol. 2000, 20, 4513-4521. [CrossRef]

32. Xiong, Y.; McCormack, M.; Li, L.; Hall, Q.; Xiang, C.; Sheen, J. Glucose-TOR Signalling Reprograms the Transcriptome and Activates Meristems. Nature 2013, 496, 181-186. [CrossRef]

33. Nishihama, R.; Ishizaki, K.; Hosaka, M.; Matsuda, Y.; Kubota, A.; Kohchi, T. Phytochrome-Mediated Regulation of Cell Division and Growth during Regeneration and Sporeling Development in the Liverwort Marchantia polymorpha. J. Plant Res. 2015, 128, 407-421. [CrossRef] [PubMed]

34. Marschner, H. Marschner's Mineral Nutrition of Higher Plants; Academic Press: Cambridge, MA, USA, 2011; ISBN 978-0-12-384906-9.

35. Rico-Reséndiz, F.; Cervantes-Pérez, S.A.; Espinal-Centeno, A.; Dipp-Álvarez, M.; Oropeza-Aburto, A.; Hurtado-Bautista, E.; Cruz-Hernández, A.; Bowman, J.L.; Ishizaki, K.; Arteaga-Vázquez, M.A.; et al. Transcriptional and Morpho-Physiological Responses of Marchantia polymorpha upon Phosphate Starvation. Int. J. Mol. Sci. 2020, 21, 8354. [CrossRef] [PubMed]

36. Asakawa, Y.; Ludwiczuk, A.; Nagashima, F. Chemical Constituents of Bryophyta. In Chemical Constituents of Bryophytes: Bio- and Chemical Diversity, Biological Activity, and Chemosystematics; Asakawa, Y., Ludwiczuk, A., Nagashima, F., Eds.; Progress in the Chemistry of Organic Natural Products; Springer: Vienna, Austria, 2013; pp. 563-605; ISBN 978-3-7091-1084-3.

37. Tyler, G. Bryophytes and Heavy Metals: A Literature Review. Bot. J. Linn. Soc. 1990, 104, 231-253. [CrossRef]

38. Bellini, E.; Maresca, V.; Betti, C.; Castiglione, M.R.; Fontanini, D.; Capocchi, A.; Sorce, C.; Borsò, M.; Bruno, L.; Sorbo, S.; et al. The Moss Leptodictyum riparium Counteracts Severe Cadmium Stress by Activation of Glutathione Transferase and Phytochelatin Synthase, but Slightly by Phytochelatins. Int. J. Mol. Sci. 2020, 21, 1583. [CrossRef]

39. Xie, C.-F.; Lou, H.-X. Secondary Metabolites in Bryophytes: An Ecological Aspect. Chem. Biodivers. 2009, 6, 303-312. [CrossRef]

40. Peters; Treutler; Döll; Kindt; Hankemeier; Neumann Chemical Diversity and Classification of Secondary Metabolites in Nine Bryophyte Species. Metabolites 2019, 9, 222. [CrossRef]

41. El-Zohri, M.H.A.; Cabala, R.; Frank, H. Quantification of Phytochelatins in Plants by Reversed-Phase HPLC-ESI-MS-MS. Anal. Bioanal. Chem. 2005, 382, 1871-1876. [CrossRef]

42. Bellini, E.; Borsò, M.; Betti, C.; Bruno, L.; Andreucci, A.; Ruffini Castiglione, M.; Saba, A.; Sanità di Toppi, L. Characterization and Quantification of Thiol-Peptides in Arabidopsis thaliana Using Combined Dilution and High Sensitivity HPLC-ESI-MS-MS. Phytochemistry 2019, 164, 215-222. [CrossRef]

43. Bellini, E.; Varotto, C.; Borsò, M.; Rugnini, L.; Bruno, L.; Sanità di Toppi, L. Eukaryotic and Prokaryotic Phytochelatin Synthases Differ Less in Functional Terms Than Previously Thought: A Comparative Analysis of Marchantia polymorpha and Geitlerinema sp. PCC 7407. Plants 2020, 9, 914. [CrossRef]

44. Schafer, F.Q.; Buettner, G.R. Redox Environment of the Cell as Viewed through the Redox State of the Glutathione Disulfide/Glutathione Couple. Free Radic. Biol. Med. 2001, 30, 1191-1212. [CrossRef] 
45. Foyer, C.H.; Noctor, G. Redox Regulation in Photosynthetic Organisms: Signaling, Acclimation, and Practical Implications. Antioxid. Redox Signal. 2008, 11, 861-905. [CrossRef] [PubMed]

46. Kneer, R.; Zenk, M.H. The Formation of Cd-Phytochelatin Complexes in Plant Cell Cultures. Phytochemistry 1997, $44,69-74$. [CrossRef] 